\title{
Numerical simulation of diesel engine using waste plastic oil blends
}

\author{
Mohanraj Chandran $^{1}$ [D Senthilkumar Tamilkolundu ${ }^{2} \cdot$ Chandrasekar Murugesan $^{2}$
}

Received: 18 March 2020 / Accepted: 24 August 2020 / Published online: 31 August 2020

(c) Springer Nature Switzerland AG 2020

\begin{abstract}
This article is focused on numerical analysis of the combustion and emission parameters on the single-cylinder directinjection (DI) engine operated in both diesel and distilled waste plastic oil blends. Analyzes of the first stage distilled waste plastic oil blends (D1WPO30) was carried out with 70:30 proportions. Simulated results are compared with experimental values in terms of cylinder pressure, heat release rate, oxides of nitrogen (NOx) and soot particles. The deviation between experimental and simulation values of cylinder pressure is found to be $1.8 \%$ with diesel whereas $6.5 \%$ with D1WPO30. The apparent heat release rate with D1WPO30 was found to be higher about $13 \%$ than diesel in simulation. The simulated NOx with D1WPO30 was found 7\% higher than with diesel fuel simulation but found $16 \%$ lesser than D1WPO30 experimentation. Similarly, the soot was found higher about $16 \%$ with D1WPO30 than diesel simulation and $17 \%$ lesser than experimental values. The CFD analysis connected with experimental studies is proven that an effective approach to predict the parameters of the in-cylinder process.
\end{abstract}

Keywords Distilled waste plastic oil · Diesel · Dl engine · CFD

\section{Introduction}

The rapid growth in the automotive sector leads the depletion the crude oil availability which causes frequent fuel price raises especially in India. In this concern, numerous investigations were carried out for the development of alternative fuel for both compression ignition $(\mathrm{Cl})$ and spark ignition (SI) engines. During the development of any alternate fuel, the emission is an important parameter which should be considered strongly because of dreads in global warming influenced cut down of greenhouse gases. In this way, the fuel was extracted using waste plastics (Polypropylene and Polyethylene) by pyrolysis process, after extraction it was distilled into two different grade fuels. The experimental analysis can be done with extracted fuel and blends on direction injection (DI) engine in-terms of performance and emission and combustion parameters. Beyond doing experimental research using extracted fuel and its blends on direction injection engine, the application of computational fluid dynamic (CFD) simulation on alternate fuels research can predict various engine combustion and emission parameters with low cost and time. The fluid flow inside the cylinder is strongly influenced by the combustion process and emission parameters. The suitability of WPO on the diesel engine is mostly based on the physical and chemical structure of WPO oil. Except for acid and sulphur content, mostly all the properties such as density, viscosity, calorific value and cetane number are similar to diesel values. This indicates that the diesel engine can run with waste plastic oil blends without any physical modifications [1]. The diesel engine can run with $30 \%$ waste plastic oil and produced better brake thermal efficiency about $40 \%$ compared with diesel operation. Also, it was evidenced with higher cylinder pressure and high heat release rate. The NOx, carbon monoxide (CO) and hydrocarbon $(\mathrm{HC})$ were found higher

\footnotetext{
$\triangle$ Mohanraj Chandran, mohan.aero@gmail.com; Senthilkumar Tamilkolundu, kmtsenthil@gmail.com; Chandrasekar Murugesan, shekarpunchu@yahoo.com | ${ }^{1}$ Department of Mechanical Engineering, M.Kumarasamy College of Engineering, Karur, India. ${ }^{2}$ Department of Mechanical Engineering, University College of Engineering (BIT Campus-Trichy), Anna University, Chennai, India.
} 
about $5 \%, 8 \%$ and $6 \%$ than diesel operations [2]. Due to higher pollutant formation and un-stable combustion in waste plastic oil (WPO) operations, few modifications are carried out on the injection timing, injection pressure and exhaust gas re-circulation. Retarded injection timing is more suitable with WPO blends than advanced injections and better atomization was attained with 220 bar of injection pressure. The $10 \%$ of exhaust gas recirculation (EGR) is with WPO blends have provided with $5 \%$ of reduction in NOx [3]. Over the last two decades, considerable progress has been made in the field of numerical studies; also it reached a mature stage in various fields like fluid flows, heat transfer, phase change problems., etc. In spite of the detailed nature of even the most comprehensive computational fluid dynamic codes, they cannot entirely predict the complete details due to complex in-cylinder mechanics in internal combustion (IC) engines.

The numerical study was carried out for diesel engine fueled by hydrogen assisted biodiesel. In addition to the reaction mechanism, the NOx, CO and soot formation mechanism was embedded. The cylinder pressure and heat release rate were increased with the increase of hydrogen addition at medium and higher loads [4]. The numerical simulation for diesel engine carried out with turbo charging and common rail direct injection. The combustion simulation carried out with pure diesel $\left(\mathrm{C}_{10} \mathrm{H}_{22}\right)$, $\mathrm{k}-\varepsilon$ viscous model and auto-ignition options. And results indicated that combustion started earlier compared to experimental results. The cylinder pressure and temperature were found higher than the experimental results. Pollutant formation and combustion efficiency were strongly influenced by fuel-air mixing and spray evaluation [5]. The CFD modelling and simulation of the combustion chamber was done using the homogeneous equation model based on the barometric equation in OpenFOAM CFD framework, also RANS $k-\varepsilon$ SST models were used for turbulence. The results from simulation have good agreement with experimental values in terms of mass and momentum flux [6]. The CFD analysis of lister 8.1 diesel engine was using AVL FIRE CFD codes was analyzed and the code includes spray atomization, mixture formation and distribution in the combustion chamber. Also, combustion simulation carried out by interaction between spray wall and spray swirl along with flow configuration. Simulated pressure, heat release rate and emissions were compared with experimental results, also it shows good agreement [7].

Using biofuels in diesel engine, the detailed combustion mechanism was created as a surrogate with simple structure by [8]. The chemical mechanism of methyl butanoate contains 264 species and 1219 reactions, later it was reduced 41 species and 150 reactions during simulation stated by [9]. The interaction between NOx and soot particles was analyzed and resulted in that effect of soot on NOx was depends not only with radiation from thermal effect but also reaction due to chemical species [10]. The Waste polyethene oil was tested on the diesel engine, and those results were compared with computer-simulated results. The numerical studies indicated that lower peak pressure and lower exhaust temperature are because of lower ignition delay, and the advanced heat release rate in premixed combustion phase with polyethene oil, also study suggest that the advanced injection timing for diesel engine operation with WPO fuels [11].

In this way, many numerical investigations of diesel engine were carried out using various alternate fuels to analyze the combustions efficiency and emission formations. But, no study was found with diesel engine simulation with waste plastic oil blends. This research is focused on CFD simulation of DI (Specification given in Table 1) engine combustion and emissions formations using diesel and first stage distilled waste plastic oil blend (D1WPO30). The heat release rate, cylinder pressure and temperature distribution are found. Also, the NOx and soot particles from combustion are identified and compared with experimental values. In this article, initially the methodology of computational domain preparation, discretization and boundary conditions are explained sequentially. Later, defining of computational equations along with combustion reactions is explained. The results from simulation such as cylinder pressure, heat release rate are explained and compared between diesel and D1WPO30 blends, also emissions of soot and NOx are discussed and compared with diesel values. Each computational results are validated with experimental results.

\section{Methodology}

The single-cylinder, constant speed and water-cooled engine were utilized for conducting the experiments. For CFD simulation, the geometry was created using the same dimensions (refer Table 1), initial and boundary conditions were set according to experimentations.

Table 1 Specification of DI engine set-up

\begin{tabular}{ll}
\hline Specifications & $\begin{array}{l}\text { Kirloskar, single cylinder, 4 stroke, } \\
\text { air cooled and Cl engine with } \\
661 \mathrm{cc}\end{array}$ \\
\hline Cylinder bore in mm & 87.5 \\
Stroke length in mm & 110 \\
Rated Power output in kW & 5.2 with 1500 rpm \\
Compression ratio & $17.5: 1$ \\
Injection pressure in bar & 200 \\
Injection timing ${ }^{\circ} \mathrm{CA}$ & 23 \\
\hline
\end{tabular}


CFD simulation was performed using ANSYS FLUENT software to estimate the in-cylinder pressure, heat release rate, the temperature distribution for distilled waste plastic oil blend and diesel. First, the combustion chamber was modelled by GAMBIT software using piston geometry and engine manufacturer data. Then, meshing was developed with size and inflation layer of 1.395 and 3 respectively. Figure 1 shows the axisymmetric model of the single-cylinder Dl engine combustion chamber after meshing. The mesh independence study was carried out using the increase of pressure in cylinder which was provided in Table 2 . Grid independence study done to prove the mesh independency of the calculations, the mesh was developed by $210,254,323,454,458,754,536,796$ and 624,565 elements. The lower levels of elements are highly influenced by the results variations. But, there was no further improvement in results after 458,754 , it only increases the time and cost of simulation. The little difference found between 458,754 and 536,796 in results and no major differences is found beyond 536,796 . Consequently, all the other simulations were carried out with 536,796 elements.

After meshing and boundary conditions selection, the mesh file was imported in ANSYS FLUENT solver. The solver was run behind $C$ codes which followed the finite volume approach. In this case, moving mesh or dynamic mesh option was used for moving boundaries. The problem was solved by using the governing equations such as continuity for species (Eq. 1) and momentum (Eq. 2) and energy (Eq. 3) for internal energy. Also, the various species were considered among these governing equations such
Table 2 Comparison of mesh analysis

\begin{tabular}{ll}
\hline No of cells at TDC & $\begin{array}{l}\text { Maximum } \\
\text { pressure in } \\
\text { bar }\end{array}$ \\
\hline 210,254 & 40.08 \\
323,454 & 41.34 \\
458,754 & 42.99 \\
536,796 & 43.14 \\
624,565 & 43.25 \\
\hline
\end{tabular}

as $\mathrm{H}, \mathrm{O}, \mathrm{OH}, \mathrm{NO}, \mathrm{N}_{2}, \mathrm{O}_{2}, \mathrm{CO}, \mathrm{CO}_{2}, \mathrm{H}_{2}$ and diesel fuel. These equations were approximated through algebraic forms on every cell, and the solutions of algebraic equations were obtained by numerical methods. The solutions might be gas motions, spray patterns, evaporation rate, mixing rate and combustion. The turbulence effects were considered by choosing $\mathrm{k}-\varepsilon$ model with wall functions by [12].

$$
\begin{aligned}
& \frac{\partial \rho m}{\partial t}+\nabla \cdot(\rho m u)=\nabla \cdot\left[\rho D \nabla\left(\frac{\rho m}{\rho}\right)\right]+\rho_{m}^{. c}+\rho^{s} \delta m 1 \\
& \frac{\partial(\rho u)}{\partial t}+\nabla \cdot(\rho m u u)=-\frac{1}{a^{2}} \nabla p-A_{0} \nabla\left(\frac{2}{3} \rho k\right)+\nabla . \sigma+F^{s}+\rho g
\end{aligned}
$$

$$
\begin{aligned}
\frac{\partial(\rho l)}{\partial t}+\nabla \cdot(\rho m u l)= & -\rho \nabla \cdot u+\left(1-A_{0}\right) \sigma / \nabla u \\
& -\nabla \cdot J+A_{0} \rho \varepsilon+Q^{c}+Q^{s}
\end{aligned}
$$

Fig. 1 Diesel engine and axisymmetric mesh model
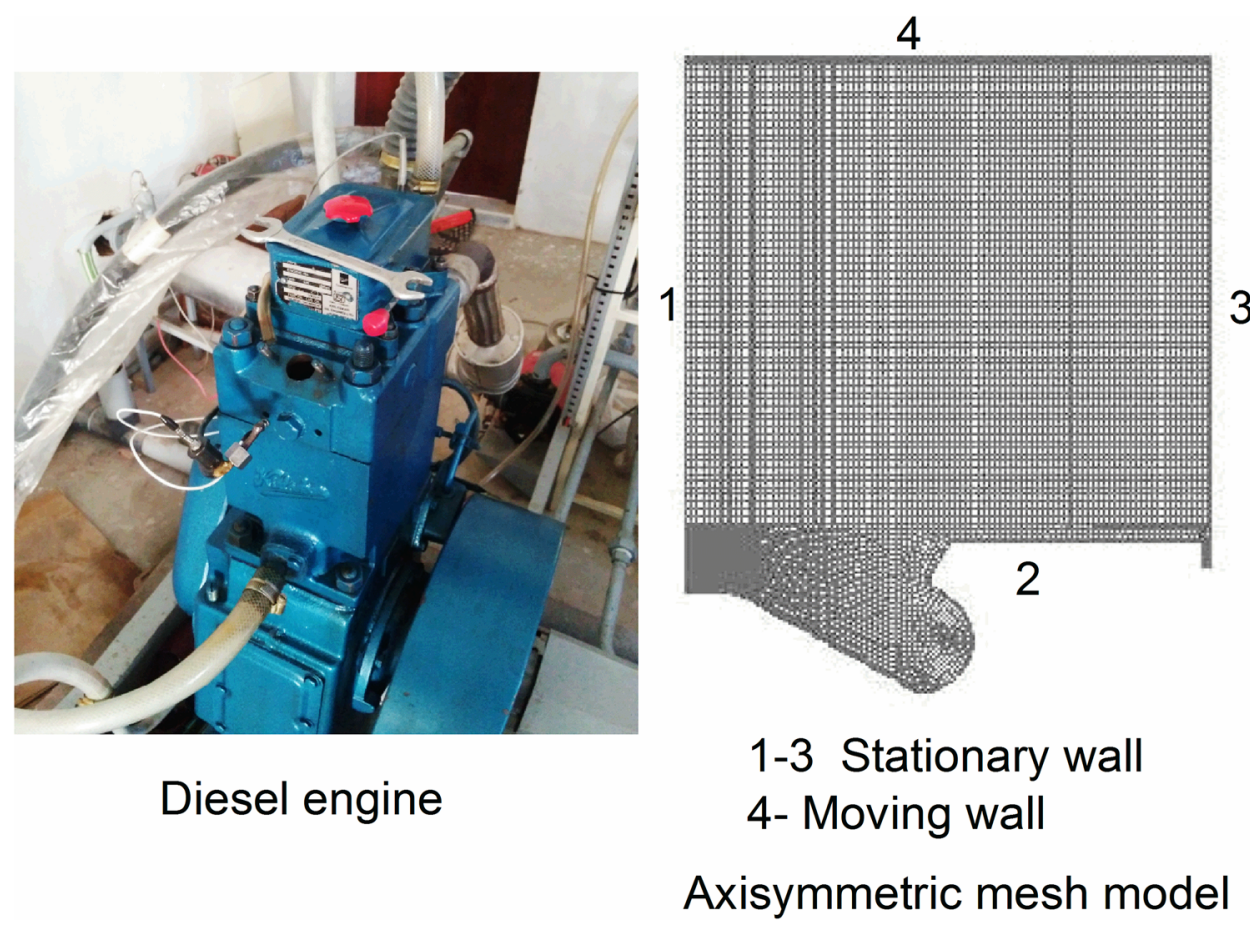
In the equations, term $\mathrm{D}$ and source terms due to $\rho_{m^{\prime}}^{c} \rho^{. s}$ , $Q^{c}$, and $Q^{s}$ are illustrated in [13].

The apparent heat release rate was calculated using Eq. 4 by [13]

$\frac{d Q_{n}}{d t}=\frac{\gamma}{\gamma-1} p \frac{d V}{d t}+\frac{\gamma}{\gamma-1} V \frac{d p}{d t}$

The following common reaction for diesel combustion is used [15]

$$
\begin{aligned}
& m_{c} \mathrm{C}_{a} \mathrm{H}_{b} \mathrm{O}_{c}+\frac{\left(b+\frac{a}{4}+\frac{c}{2}\right)}{\phi}\left(\mathrm{O}_{2}+3.7 \mathrm{~N}_{2}\right) \rightarrow x_{1} \mathrm{H}_{2} \mathrm{O}+x_{2} \mathrm{H}_{2}+x_{3} \mathrm{OH}+x_{4} \mathrm{H}+x_{5} \mathrm{~N}_{2} \\
& +x_{6} \mathrm{NO}+x_{7} \mathrm{CO}_{2}+x_{8} \mathrm{CO}+x_{9} \mathrm{O}_{2}+x_{10} \mathrm{O}
\end{aligned}
$$

manufacturer's documents refer to Table 2 [14]. For evaluation of combustion chemistry, species transport model was used. Combustion simulation was initiated at intake valve closing (IVC) with an initial pressure of 3.45 bar, Temperature at $404 \mathrm{~K}$, species mass fraction of $\mathrm{O}_{2}=0.2369, \mathrm{~N}_{2}=0.7473, \mathrm{CO}_{2}=0.0789, \mathrm{H}_{2} \mathrm{O}=0.0369$. Fuel $\left(\mathrm{C}_{12} \mathrm{H}_{23}\right)$ was used as a surrogate for diesel fuel and was injected 23 degrees before compression (Top Dead Centre). Engine rpm was kept constant at about $1500 \mathrm{rpm}$
The chemical equilibrium between reactants and products in diesel combustion with air is found using the above model. There were ten combustion species are assumed to form the general combustion equation. In the cylinder, the mass of fuel burned and mass of air- entrained the combustion species concentration at any instant is given temperature is determined using conservation of mass on $\mathrm{C}-\mathrm{H}-\mathrm{O}-\mathrm{N}$.

$N O+N \Leftrightarrow O+N 2$

$N 2+O \Leftrightarrow N O+O$

$\mathrm{N}+\mathrm{OH} \Leftrightarrow \mathrm{NO}+\mathrm{H}$

The widely accepted [16] NO formation in diesel combustion is presented by above chemical equations. The basic theories of kinetics in the form of the differential equation are used to determine the concentration of $\mathrm{NOx}$ during the combustion process.

For the formation of soot particles, the following equations are formed by [17] to predict the soot particles between soot formed at early stages of combustion and soot particles oxidized later stages of combustion.

$\frac{d m_{s f}}{d t}=A_{s f} m_{f b}^{0.8} p^{0.5} \exp \left(-E_{s f} / R_{m o l} T\right)$

$\frac{d m_{s o}}{d t}=A_{s o}\left(P_{O_{2}} / P\right) P^{1.8} \exp \left(-E_{s c} / R_{m o l} T\right)$

where sf and so are soot formed and soot oxidized respectively. Mfb is mass of fuel burned in $\mathrm{kg} / \mathrm{s}$ and $\mathrm{P}$ is a partial pressure of oxygen in MPa. Esf and Esc are the activation energies during forming and oxidation.

The engine valve timing, engine pressure and its profile and other related data were obtained from the and its effect on unburnt fuel was examined. For pure diesel and distilled waste plastic oil with diesel blends (30\% DWPO + 70\% diesel)-the chemical formula, $\mathrm{C}_{13.18}$ $\mathrm{H}_{23.56}$ is used for simulations.

\subsection{Spray modeling}

Combining the above mentioned Renolds Navier stokes (RANS) equations with turbulence model, the gas flow inside the IC engine has been formulated. For spray modelling, discrete droplet phase was used. It is denoted as the discrete phase model in Ansys Fluent conventional code. This model is considered as a continuum which is formulated by solving averaged Navier stokes equation. Similarly, the dispersed phase is calculated by the number of particles, droplets while mass, momentum and energy exchange. For this model, statistical problem prediction is needed for representation of the finite number of particles. Each considered particle should represent the group which has exact no of particles and identical characteristics such as position, velocity, temperature, size and density. One particle consideration in a group may reduce the computational effects in CFD modelling.

Initial conditions of the particles such as position, velocity, size etc. are assumed to be known. Initial break up or injector option was not considered in the case of liquid spray, and the whole mass was given in the liquid form. Due to time and surroundings, the mass and energy exchange occurs in fluid phase and particle. Therefore, two sets of equations were considered, one for fluid phase and another for the particle phase. The coupling of these two equations was done in by two different ways, one was gas displacement by the volume occupied by the particles and the other was momentum exchange between particles and gases. 


\subsection{Transport of droplets}

The particle trajectory was given in Lagrangian plane and it was obtained by integrating the force balance, on the particle. This equation is given in $x$ direction, using the cartesian coordinate system

$\frac{d u_{p}}{d t}=F_{D} \cdot\left(u-u_{p}\right)+\frac{g_{x}\left(\rho_{p}-\rho\right)}{\rho_{p}}+F_{x}$

where $\mathrm{Fx}$ is force per unit mass, $\mathrm{Fd}$ is drag force, $\mathrm{U}$ is fluid velocity, Up is particle velocity, $\rho$ is fluid density and $\rho p$ is particle density.

In Ansys Fluent, the drag force is given as

$F_{D}=\frac{18 \mu}{\rho_{p} d_{p}^{2}} \frac{C_{D} \operatorname{Re}_{p}}{24}$

where $\mathrm{Dp}$ is particle diameter $\mathrm{Cd}$ is co-efficient of drag and $\mathrm{Re}_{\mathrm{p}}$ is relative Reynolds number for particles

It was considered as important to analyze the computational analysis of in-cylinder during later part of compression and the initial part of expansion stroke in the diesel engine. During this period, operations including fuel injection, fuel-air mixing, combustion and emission formation took place. Hence current analysis was considered from $40^{\circ} \mathrm{CA}$ before top dead centre (TDC) $\left(320^{\circ} \mathrm{CA}\right)$ during compression to $60^{\circ} \mathrm{CA}$ after TDC $\left(420^{\circ} \mathrm{CA}\right)$ during expansion. The inlet and outlet were considered as constant pressure boundaries. Normally, the top and bottom most point of the cylinder where the end of piston motion is denoted by the top dead centre and bottom dead centre.

Combustion simulation was started at IVC (intake valve Closing) with initial conditions as 3.4 bar and $405 \mathrm{~K}$, species mass fraction of $\mathrm{O}_{2}=0.1369, \mathrm{~N}_{2}=0.7473, \mathrm{CO}_{2}=0.0789$, $\mathrm{H}_{2} \mathrm{O}=0.0369$. Diesel $\left(\mathrm{C}_{12} \mathrm{H}_{23}\right)$ fuel and blended waste plastic oil $\left(\mathrm{C}_{13.18} \mathrm{H}_{23.56}\right)$ were used as fuel and simulated separately. Also, fuel was injected at 23 degrees before compression (Top Dead Centre). Engine rpm was constant about 1500 RPM. Turbulence intensity was about $5 \%$ and the mixing length scale was $1 \mathrm{~mm}$. Friction between flow and wall was not considered, also smooth wall option was enabled during turbulence flow at the wall. The boundary conditions for side and bottom walls are mentioned as a stationary wall. And the top wall is mentioned as a moving wall by dynamic mesh. Two different cases such as pure diesel and distilled waste plastic oil with diesel blends (30\% D1WPO + 70\% diesel) considered for simulation. IC engine in-cylinder model was adopted for the simulation and velocity, pressure and temperature contours were simulated for different crank angles. Also, static pressure and apparent heat release rate were drawn for all the crank angles after simulation gets over. The assumed wall temperatures at the engine speed of $1500 \mathrm{rpm}$, was $482 \mathrm{~K}$ under $50 \%$ load.

\section{Results and discussion}

The potential of the axisymmetric models for defining flow and combustion process in their full detail is highly promising. However, the results of these models have to be validated against experimental results conducted by [2].

\subsection{Cylinder pressure variations}

Pressures obtained from the experimental work and CFD simulations using diesel fuel were compared and are shown in Fig. 2. Using this plot, both experimental and predicted pressure was compared for validation. The small difference between experimental and predicated pressure was observed. The cylinder peak pressure in experimental and simulated values was found to be 68.8 bar at $367^{\circ} \mathrm{CA}$ and 73.45 bar at $373^{\circ} \mathrm{CA}$. Also from Fig. 2 , it is clear that pressure with simulated values is a little higher than that obtained from the experimental work. This higher pressure with simulation was because of assuming the friction free simulation.

Figure 3 presents the comparative view of experimental and predicted values using D1WPO30 as fuel. Similar to diesel fuel results, predicted cylinder pressure using D1WPO30 was found higher than experimental values.

The reasons for this observed increased pressure in simulations could be:

(a) The difference in ignition delay ( In case of experimental work, ignition delay may cause the combustion to continue even after the piston crosses TDC towards expansion stroke which results in the lower peak cylinder pressure)

(b) Absence of inlet and exhaust port

(c) Blow by and crevice flows were not considered.

(d) Due to computational limitations, the complete chemical composition of D1WPO30 was not considered for simulation.

\subsection{Temperature distribution}

Figure 4 shows that simulated values of temperature distribution against crank angle for both diesel and D1WPO30. The maximum temperature found was $1032 \mathrm{~K}$ at $378^{\circ} \mathrm{CA}$ with diesel, $1058 \mathrm{~K}$ at $383^{\circ} \mathrm{CA}$ with D1WPO30.

Also Fig. 5 presents the comparison of the apparent heat release rate of both diesel and D1WPO30. The maximum heat release rate was found to be about $336.3 \mathrm{~J} /$ Deg at $362^{\circ} \mathrm{CA}$ with diesel and $387.2 \mathrm{~J} / \mathrm{Deg}$ at $363^{\circ} \mathrm{CA}$ 
Fig. 2 Comparison of simulated value with experimental values of cylinder pressure (diesel fuel)

Fig. 3 Comparison of simulated value with experimental values of cylinder pressure (D1WPO30)
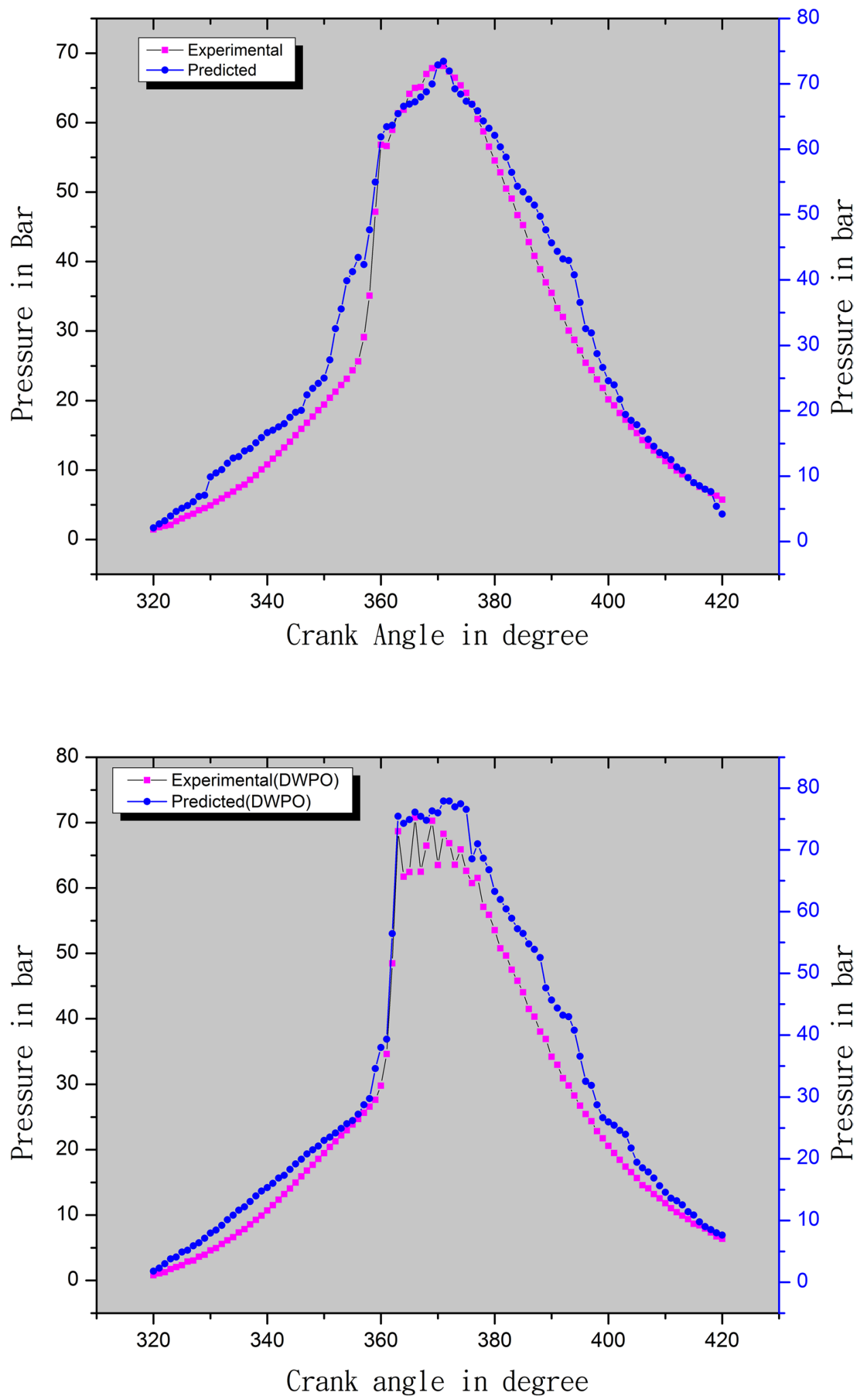
Fig. 4 Temperature distribution versus crank angle

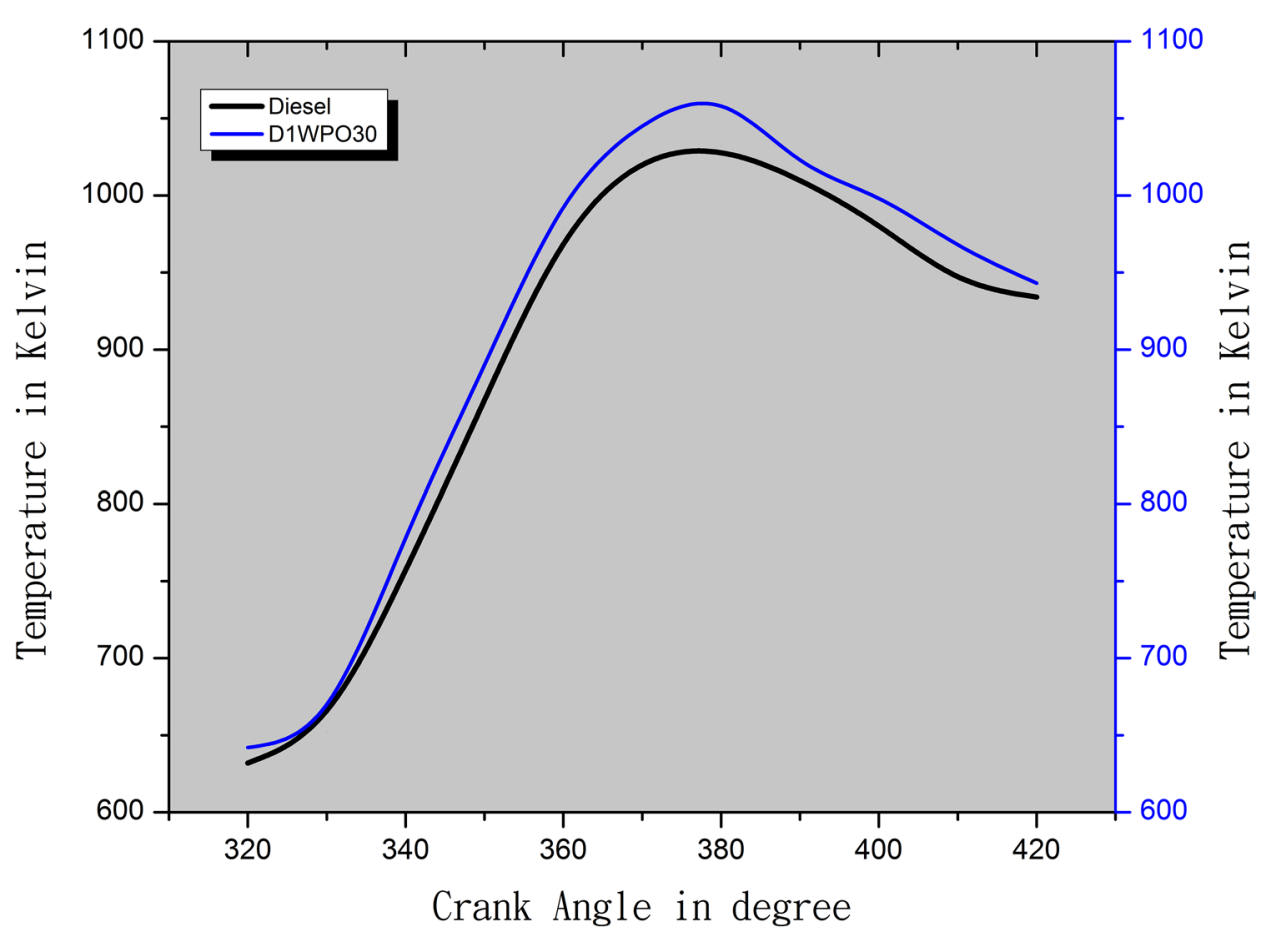

Fig. 5 Apparent heat release rate versus crank angle

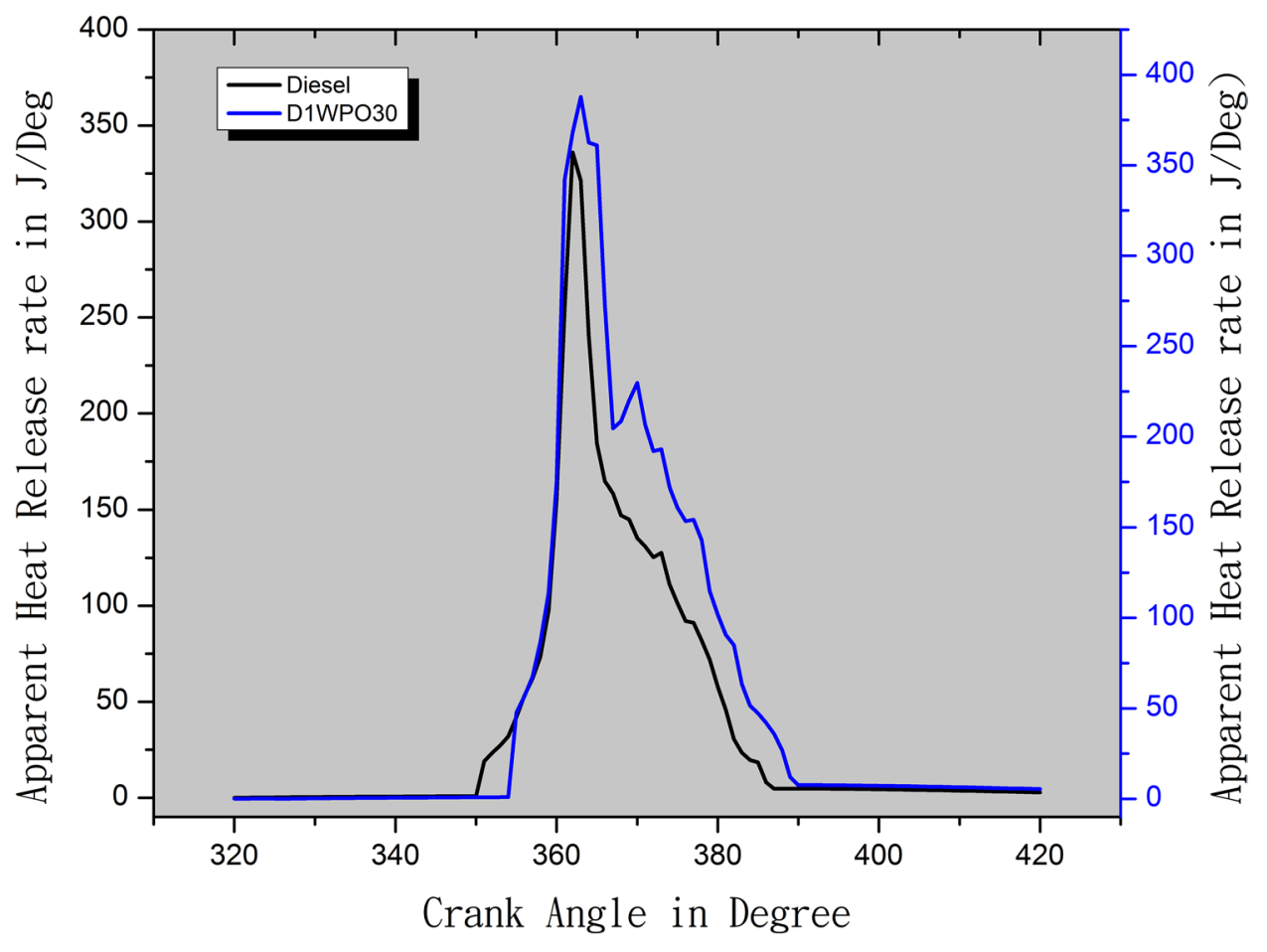

\subsection{Temperature and velocity contours for D1WP030}

The Fig. 6 shows that temperature distribution contours for diesel fuel and D1WPO30 simulations. No major difference was found while comparing both diesel and D1WPO30 temperature contour patterns. But the 
Fig. 6 Temperature distributions with diesel and D1WPO30 at different crank angle

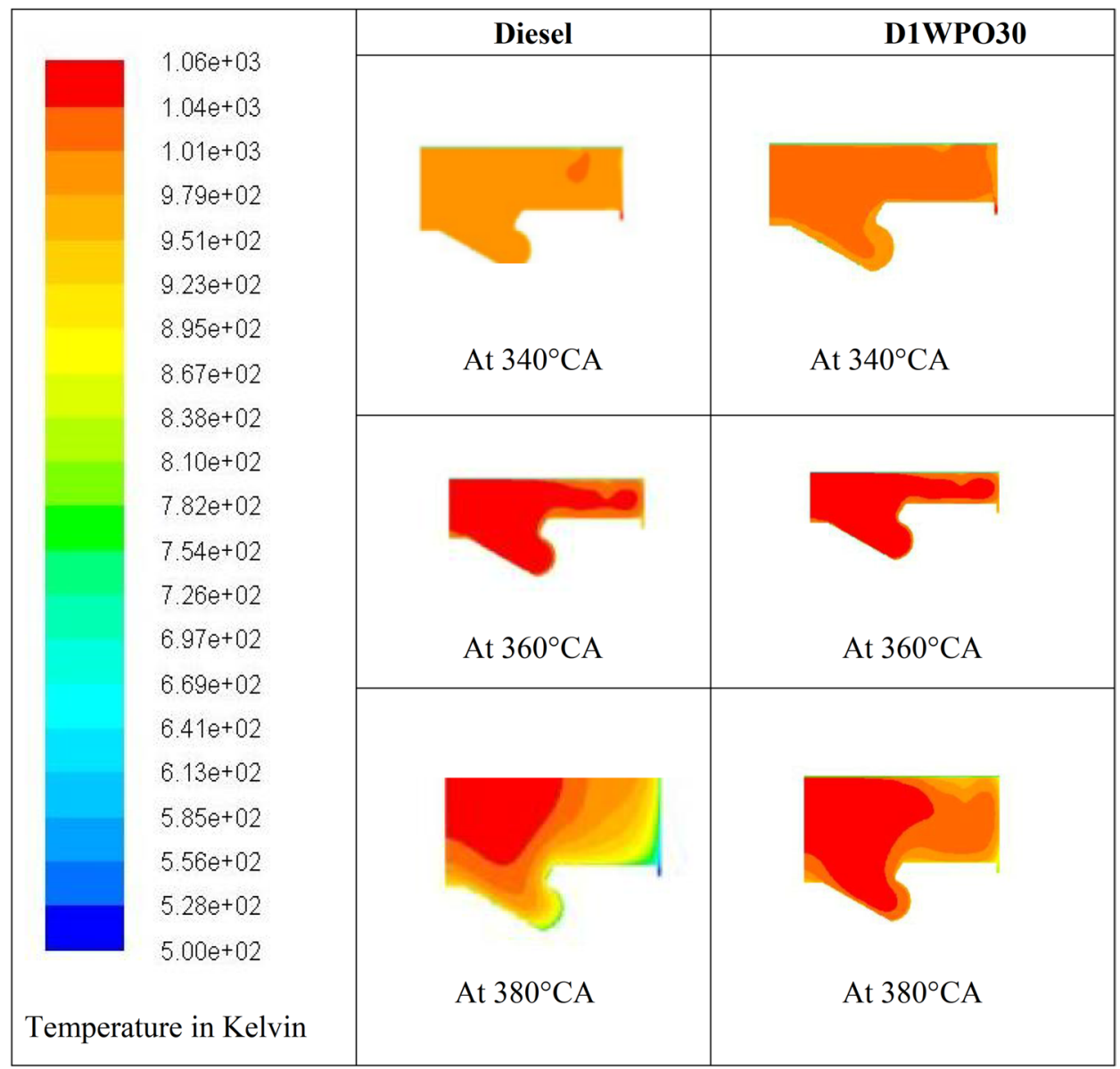

maximum temperature throughout the process was found with D1WPO30 and not with diesel; this was due to higher hydrocarbon values of D1WPO30. At crank angle $320^{\circ} \mathrm{CA}$, the temperature increased up to $920 \mathrm{~K}$. Mostly uniform temperature distributions were found throughout the combustion at all crank angle; this indicated that better combustion was attained using D1WPO30 like diesel fuel. The maximum temperature attained by this combustion was noted to be about $1060 \mathrm{~K}$.

The Fig. 7 presents the velocity distribution contours during combustion using D1WPO30. It indicates that lower velocity was found at the centre portion of working volume than near the walls. This was mainly because of lower swirl value during compression and combustion. Normally, swirl value is higher during intake stroke due to sucking operation, and then it gets reduced during compression and combustion processes. But during fuel injection, swirl gets enhanced by fuel molecules. The velocity patterns for both diesel and D1WPO30 were similar, but the velocity magnitude was higher with diesel than with D1WPO30; this was mainly due to lower cylinder pressure with diesel fuel combustion.

\subsection{Emission parameters}

In this section, NOx and soot particles in emission from the combustion chamber are discussed. Exhaust NOx and soot particle values are compared and validated with experimental values for both cases. The comparative analysis shows that simulated values are in better agreement with experiment values for $50 \%$ loading condition.

\subsection{Nitrous oxide}

In Fig. 8, the simulation result shows that NOx elements in emission were found maximum with D1WPO30 than diesel values. This is due to increasing temperature rate in the D1WPO30 fuel than diesel. Comparing simulated values and experimental values, the little deviation was identified, also a simulated value was found lower than experimental values. The maximum NOx values in simulation with diesel and D1WPO30 were $2.13 \mathrm{~g} / \mathrm{kW} \mathrm{h}$ and $2.30 \mathrm{~g} / \mathrm{kW}$ h respectively. 
Fig. 7 Velocity distribution with diesel and D1WPO30 at different crank angle
Fig. 8 NOx formations with diesel and D1WPO30

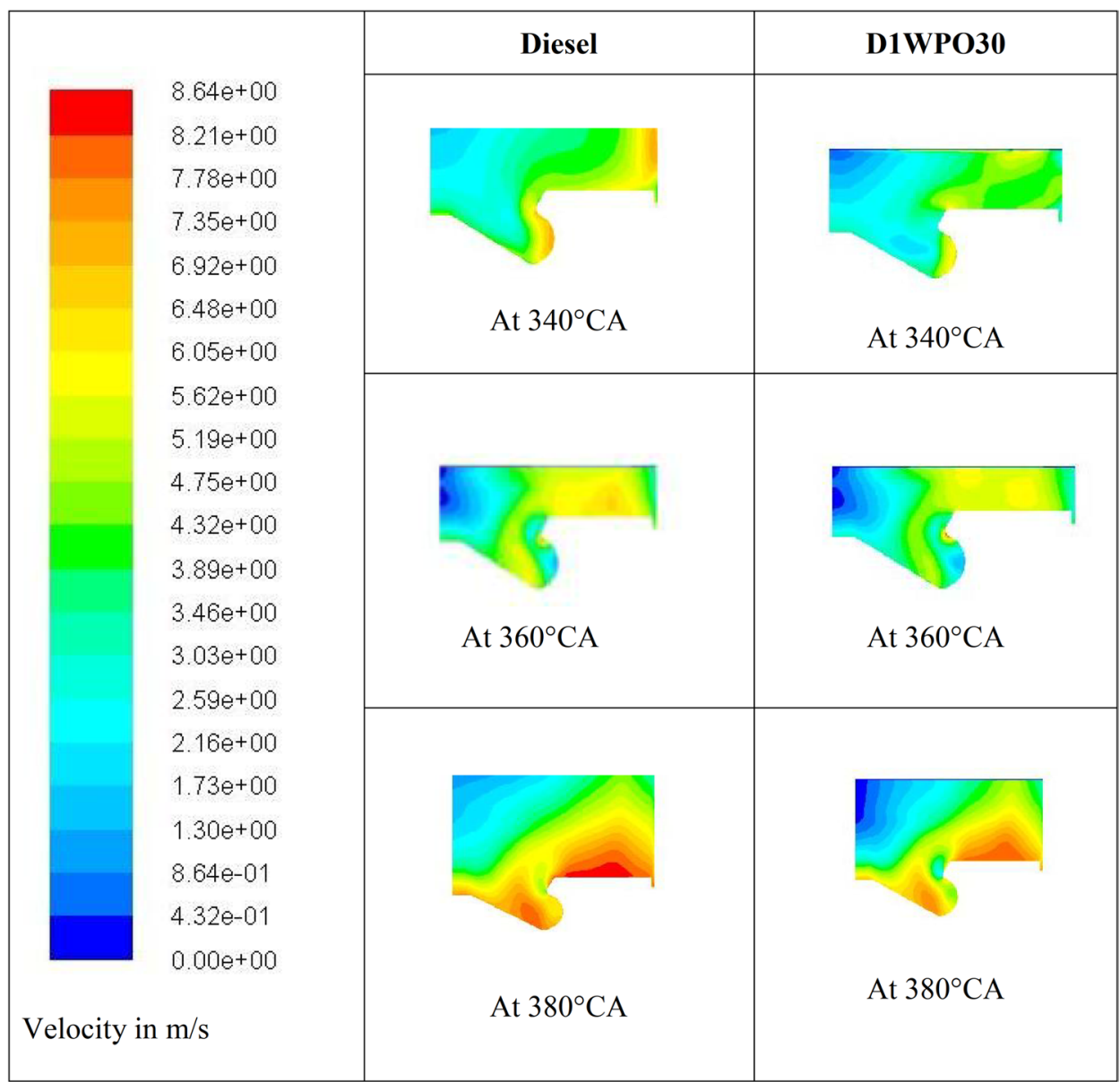

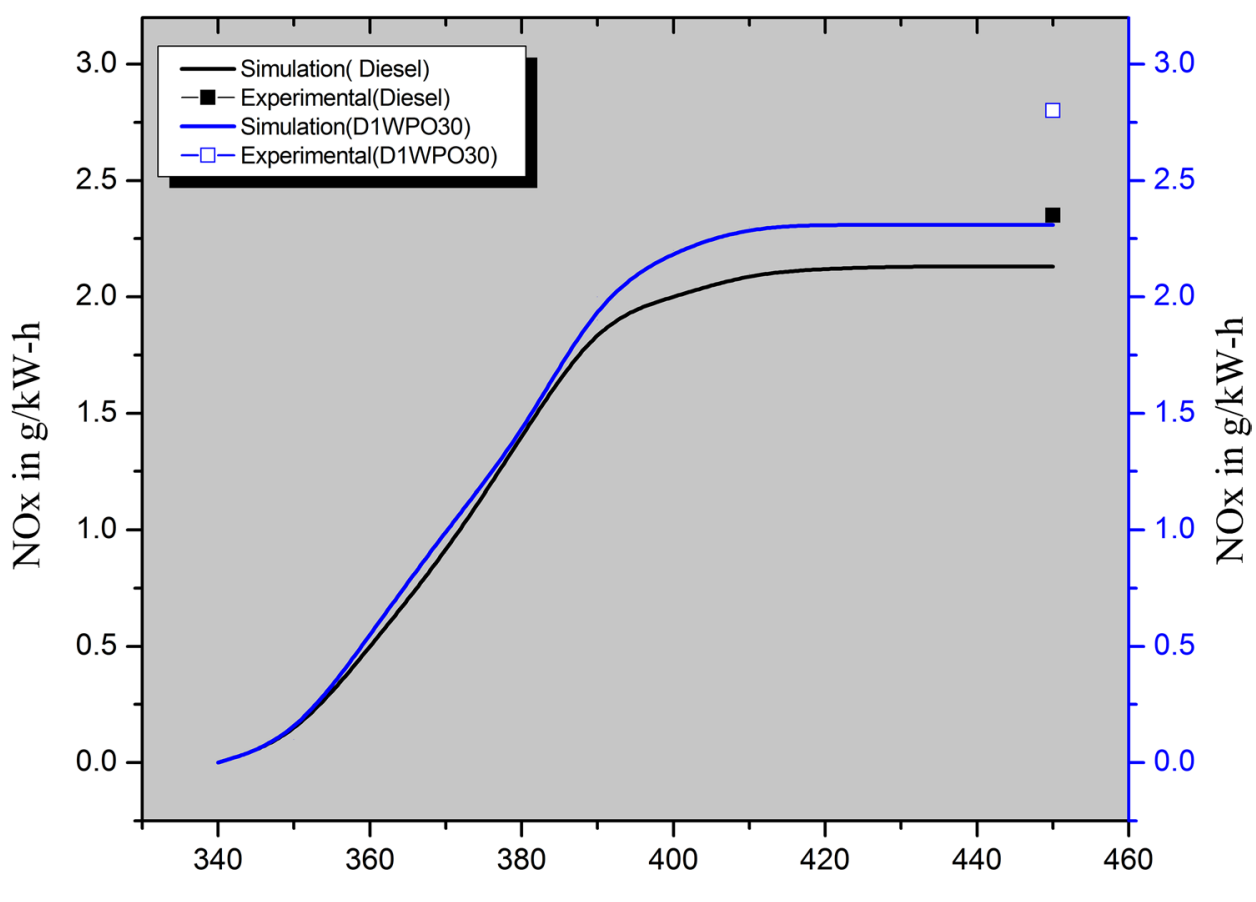

Crank Angle in degree 
Fig. 9 Soot formations in diesel and D1WPO30

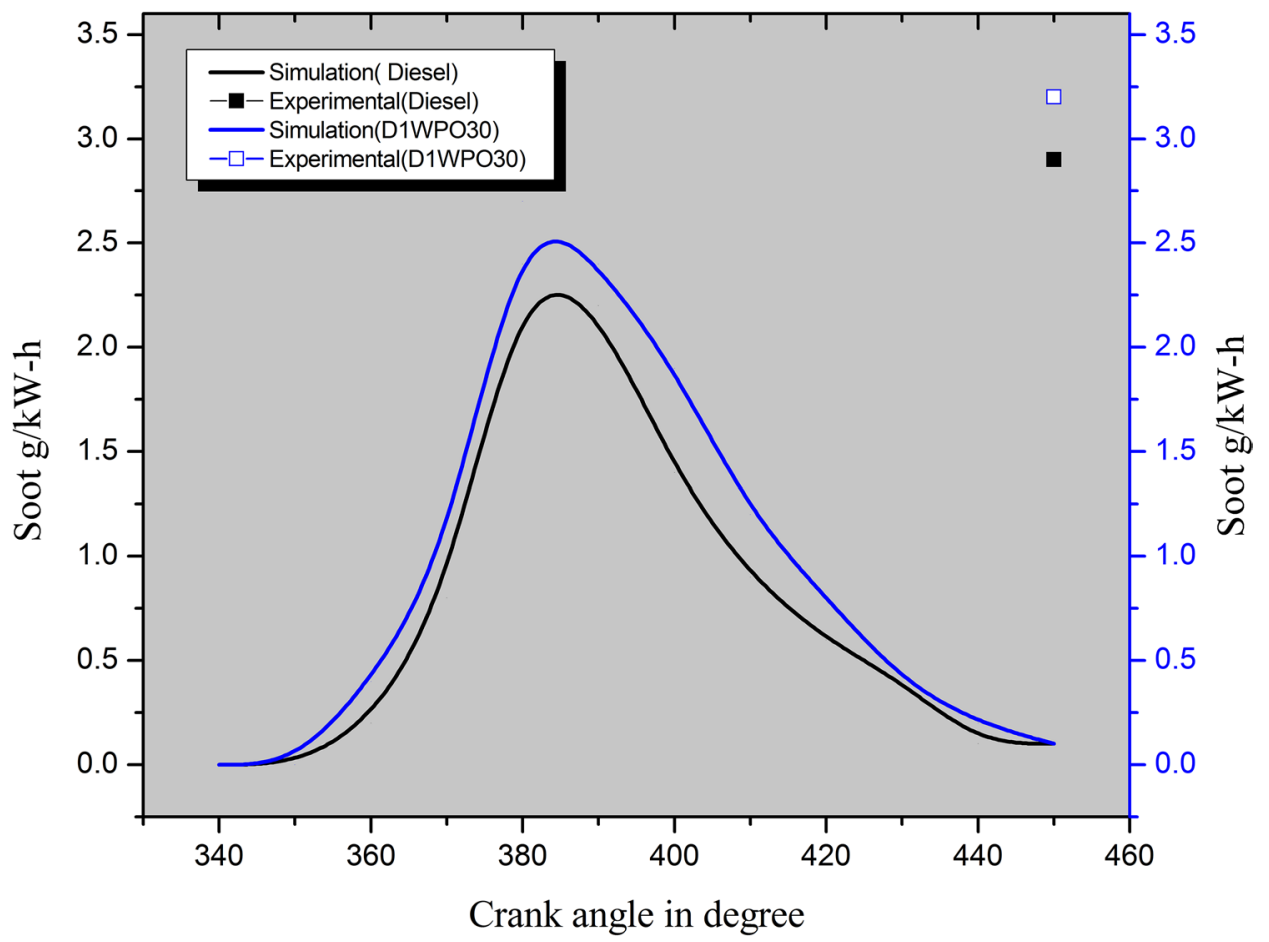

\subsection{Soot particles}

The soot particles production during combustion has presented in Fig. 9. The soot formation with D1WPO30 found higher than diesel fuel. Due to little uncertainties with soot measuring equipment and difficult to predict the complete combustion phenomena, the small deviation found between experimental and simulated values of soot particles. The maximum soot values with diesel and D1WPO30 recorded as $2.4 \mathrm{~g} \mathrm{~kW} \mathrm{~h}$ and $2.7 \mathrm{~g} / \mathrm{kW} \mathrm{h}$ respectively.

\section{Conclusion}

An axisymmetrical computational fluid dynamic analysis was carried out for diesel and D1WPO30. The deviation between the experimental and simulation was very small, which might have been caused by both experimental uncertainties and limitations of computational fluid dynamics. The predicted cylinder pressure was found to be higher than the experimental values for both diesel and D1WPO30 operations. The maximum and better temperature distribution was found with D1WPO30 than diesel fuel. The higher apparent heat release rate was found with D1WPO30 than diesel; this was due to higher hydrocarbon values incorporations with D1WPO30. The both NOx and soot formations were found higher with D1WPO30 than diesel as like experimentations. The NOx increased up to $8 \%$ and soot particles increased up to $12 \%$ with D1WPO30 than diesel. From this investigation, the CFD approach on DI engine operation is a proven technique to analyze the combustion and emission parameters before conducting experiments. Also, adding the influence in changes of injection timing and an injection pressure of fuel to combustion performance and emission will provide a better way to predict the optimal usage of D1WPO30 in diesel engines.

\section{References}

1. Kalargaris I, Tian G, Sai Gu (2017) The utilisation of oils produced from plastic waste at different pyrolysis temperatures in a DI diesel engine. Energy. https://doi.org/10.1016/j.energ y.2017.05.024

2. Chandran M, Tamilkolundu S, Murugesan C (2018) Investigation of the performance, combustion parameters, and emissions analysis on DI engine using two staged distilled waste plastic oil-diesel blends. Therm Sci 22(3):1469-1480

3. Muthuvel M, Govindan N (2009) Influence of injection timing on performance, emission and combustion characteristics of a Dl diesel engine running on waste plastic oil. Energy 34(10):1617-1623. https://doi.org/10.1016/j.energ y.2009.07.010

4. An H, Yang WM, Maghbouli A, Li SKJ, Chou Chua KJ, Wang JX, Li L (2013) Numerical investigation on the combustion and emission characteristics of a hydrogen assisted biodiesel combustion in a diesel engine. Fuel 120:186-194

5. Wang G-J, Chiang C-J, Su Y-H (2013) CFD modeling of a turbocharged common-rail diesel engine, 2013. JSAE 20139103/SAE 2013-32-9103

6. Tahmasebi E, Lucchini T, D'Errico G, Onorati A (2015) Numerical simulation of diesel injector internal flow field. Energy Procedia 82:51-58

\section{SN Applied Sciences}


7. Barzegar R, Shafee S, Khalilarya S (2013) Computational fluid dynamics simulation of the combustion process, emission formation and the flow field in an in-direct injection diesel engine. Therm Sci 17:11-23

8. Gail S, Sarathy SM, Thomson MJ, Diévart P, Dagaut P (2008) Experimental and chemical kinetic modeling study of small methyl esters oxidation: methyl (E)-2-butenoate and methyl butanoate. Combust Flame 155(4):635-650

9. Fisher EM, PitzWJ CHJ, Westbrook CK (2000) Detailed chemical kinetic mechanisms for combustion of oxygenated fuels. Proc Combust Inst 28:1579-1586

10. Guo H, Smallwood GJ (2007) The interaction between soot and NO formation in a laminar axisymmetric coflow ethylene/air diffusion flame. Combust Flame 149(1-2):225-233

11. Naima K, Liazid A, Tazerout M, Bousb H (2018) Experimental and numerical investigation of combustion behaviour in diesel engine fuelled with waste polyethylene oil. J Eng Sci Technol 13(10):3204-3219

12. Rosen A (1989) KIVA-Il: a computer program for chemically reactive flows with sprays. New Mexico: Los Alamos National Laboratory: University of California for the United States
13. Pedrozo VB, May I, Dalla Nora M, Cairns A, Zhao H (2016) Experimental analysis of ethanol dual fuel combustion in a heavyduty diesel engine: an optimization at low load. Appl Energy 165:166-182. https://doi.org/10.1016/j.apenergy.2015.12.052

14. https://drive.google.com/file/d/OBxpHpyYTEWVdV0xPRUt EVmRacG8/view

15. Sindhu R, Amba Prasad Rao G, Madhu Murthy K (2018) Effective reduction of NOx emissions from diesel engine using split injections. Alex Eng J 57:1379-1392

16. Lavoie GA, Heywood JB, Keck JC (1970) Experimental and theoretical study of nitric oxide formation in internal combustion engines. Combust Sci Technol 1(4):313-326

17. Lipkea WH, DeJoode AD (1994) Direct injection diesel engine soot modeling: formulation and results. Technical Report, SAE Technical Paper, 1994

Publisher's Note Springer Nature remains neutral with regard to jurisdictional claims in published maps and institutional affiliations. 